\title{
The Role of Innovative Concordnacing Instruction Method in Improving Iranian EFL learners' Vocabulary
}

\section{Alireza Karbalaei ${ }^{* 1} \&$ Mohsen Kord Afshari $^{2}$}

* Correspondence:

Karbalaei2008@gmail.com

1. Department of English, Farhangian

University, Tehran, Iran

2. Department of ELT, Ayatollah

Amoli Branch, Islamic Azad

University, Amol, Iran

Received: 26 March 2019

Revision: 17 May 2019

Accepted: 30 August 2019

Published online: 20 September 2019

\begin{abstract}
Vocabulary plays a pivotal role in second language learning and development. Concordance-based methods are considered as new techniques for improving teaching materials and motivating learners to improve their language ability with authentic texts. To this end, the present study aims to enhance the effect of Innovative Concordancing Instruction (ICI) on vocabulary knowledge by integrating principled instructional approaches. The participants included 90 university students at undergraduate level in Islamic Azad University in Tehran, Iran. First, after giving a proficiency test, the students were divided into innovative concordancing, traditional concordancing and control group. The participants in both experimental groups were given eight-week vocabulary instruction, while no special vocabulary instruction was considered for the sample in the control group. Based on the results, ICI had both better immediate and delayed instructional effects on increasing receptive and productive knowledge although the students in instructional groups improved in terms of receptive and productive knowledge. The present study could present some implications for teaching vocabulary when designing vocabulary curricula and developing materials for EFL learners and teachers.
\end{abstract}

Keywords: Innovative concordancing instruction, traditional concordancing instruction, vocabulary, EFL context 


\section{Introduction}

Vocabulary is a crucial element for second language learning and second language development. Learners need sufficient vocabulary in order to be able to perform different language activities. In other words, when reading, writing, listening, or speaking, learners need to have enough vocabulary in order to understand and to be understood (Meara \& Fitzpatrick, 2000; Read, 2000). Vocabulary learning, however, is a long and gradual process. Learners need to have multiple exposures to words and know different aspects of a word before they can learn and actually use them in their production. Different from native speakers who have tremendous exposure to new words in different contexts all their lives, second/foreign language learners do not have the same opportunities.

Concordance-based methods are seen as offering new and exciting techniques for developing teaching materials and enabling learners to make direct discoveries about language, especially vocabulary, and improve their language ability with authentic texts. This type of instruction makes use of a sophisticated computer program called a concordancer. A concordancer allows learners to search how a word is used in sentences. Tim Johns, the pioneer of data-driven learning, and other researchers (Cobb, 1999; Hunston, 2002) have appealed for more empirical research to investigate concordance effects on learners' language acquisition.

In spite of the fact that concordancing instruction has been around in the field of vocabulary learning for years and seems to be a promising teaching method to develop learners' vocabulary knowledge, to date, only a handful small scale studies have been conducted to examine the effects of concordancing on vocabulary acquisition (Cobb, 1999; Kaur \& Kegelheimer, 2005). Moreover, these studies failed to show whether concordancing instruction can help enhance productive vocabulary knowledge.

Reviews of previous literature concerning pedagogical principles showed that learners need to be instructed under appropriate learning conditions in order for word learning to occur (e.g., repeating and recycling, reflection, taskinduced involvement) (DeCarrio, 2001; Schmitt, 2008). It was found, however, that previous studies of concordancing instruction did not incorporate those learning principles into their concordancing classes. As such, it would be beneficial for learners and the fields of vocabulary instruction and concordancing instruction if a study integrated concordancing instruction with principled instructional approaches in order to enhance both receptive and productive vocabulary knowledge.

\subsection{Statement of the Problem}

According to Schmitt (1998), learning words by considering different aspects of word knowledge is a long and incremental process. Second language learners, particularly learners in an EFL context, have limited exposure to words. These learners usually receive only two to three hours of formal English instruction per week, and they have no or little exposure to the target language outside class. In such a context, it is hard for learners to develop an understanding of different aspects of much-needed words, such as academic words, yet these words are one critical element to help learners perform well and succeed in their academic classes. With the innovative technology in language learning, the use of concordance-based methods may help enhance ESL/EFL learners in the learning of the much-needed words.

Previous studies have shown that learners receiving concordancing instruction outperformed learners receiving conventional vocabulary instruction in the measures of definitional knowledge and limited production (gap-filling) (Horst, Cobb, \& Nicolae, 2005). Only two studies, one by Kaur and Hegelheimer (2005) and the other by Horst, Cobb, and Nicolae (2005) looked at learners' use of taught words in actual production. These studies, however, failed to show that concordancing instruction led to the use of taught words in learners' actual production. Regarding Iranian context, no study, to the best of our knowledge, has compared the effect of innovative and traditional concordnacing instruction method on learning vocabulary.

\subsection{Research Questions}

By considering the above-mentioned background, the current study attempts to increase the effectiveness of concordancing instruction on vocabulary knowledge by integrating principled instructional approaches. This new method developed for this study is called innovative concordancing instruction. The main purpose of this study is to compare the effects of the innovative concordancing instruction on receptive and productive vocabulary knowledge with traditional concordancing, conventional vocabulary methods, and a control group across Iranian EFL learners. Based on these purposes, the following research questions were raised: 
Research question 1: Does innovative concordancing instruction result in receptive vocabulary learning when compared to traditional concordancing instruction method?

Research question 2: Does innovative concordancing instruction result in productive vocabulary learning when compared to traditional concordancing instruction method?

Research question 3: Does innovative concordancing instruction result in learners' retention of vocabulary knowledge when compared to traditional concordancing instruction method?

Research question 4: Does innovative concordancing instruction help learners retain their receptive vocabulary when compared to traditional concordancing instruction method?

\subsection{Research Hypotheses}

The hypotheses of this study were as follows:

Research hypothesis 1: Innovative concordancing instruction does not result in receptive vocabulary learning when compared to traditional concordancing instruction method.

Research hypothesis 2: Innovative concordancing instruction does not result in productive vocabulary learning when compared to traditional concordancing instruction method.

Research hypothesis 3: Innovative concordancing instruction does not result in learners' retention of vocabulary knowledge when compared to traditional concordancing instruction method.

Research hypothesis 4: Innovative concordancing instruction cannot help learners retain their receptive vocabulary when compared to traditional concordancing instruction method.

\section{Review of the Literature}

\subsection{Types of Traditional Vocabulary Instruction in Concordancing Studies}

From reviewing the literature, I found three empirical concordancing studies that have explicitly claimed to compare traditional or conventional vocabulary instructions with vocabulary instruction incorporating concordancers. These are studies by Gan, Low, and Yaakub (1996), Supathranon (2005), and Kaur and Hegelhiemer (2005). In Gan, Low, and Yaakub (1996) and Supathranon's (2005) studies, the traditional instruction group received instruction (i.e., lecture, written exercises, and using a dictionary) that focused on developing word attack skills, while the experimental instruction group received concordancing lines and training on how to use concordancers in word attack skills exercises. Word attack skills were such as using context clues, affixes, and learning about collocations and parts of speech. The rationale for using word attack skills in Gan, Low, and Yaakub's (1996) study was based on the researchers' perceptions of learners' needs. In Supathranon's (2005) study, the rationale was to enable students to utilize different lexical knowledge to deal with unknown words in new reading articles. In another study, Kaur and Hegelheimer (2005) identified traditional or conventional as using online dictionaries to learn academic words. This group was compared with the experimental group who had access to both online dictionaries and concordancers.

\subsection{Types of Traditional Vocabulary Instruction in Non-concordancing Studies}

In a non-concordancing study, de la Fuente (2006) compared task-based vocabulary instruction with traditional instruction. Traditional in this case referred to presentation, practice, and production (PPP). In the presentation stage, the teacher presented the meaning of the target words. In the practice stage, learners repeated the words in pattern drills, matching exercises, and fixed dialogues. In the production stage, learners produced the target words in an open situation (i.e., role play). The rationale for PPP was that language was best learned when its elements were presented in logical sequences.

Apart from the comparative study described above, others have not claimed to compare their method with traditional ones. However, what is commonly used as a comparison group is learning vocabulary through reading. The rationale was that vocabulary could be learned incidentally while reading. The notion was that reading supplied context for unknown words and multiple exposures of them. Yet, other studies have argued that learning vocabulary via extensive reading is insufficient in foreign language classroom contexts (Atay \& Kurt, 2006; Laufer, 2003; Laufer \& Hulsjin, 2001). Therefore, these studies compared learners who learned vocabulary through reading with learners who learned vocabulary through another method or extra word focus exercises. Laufer (2003), for example, compared the 
effectiveness of learning vocabulary via three word-focus tasks with learning vocabulary through reading only. Results showed that more words were acquired through the word-focus tasks. Paribahkt and Wesche (1998) compared learners in a reading-only group with learners in a reading-plus vocabulary exercise and found that the latter group demonstrated larger gains on target vocabulary knowledge. As an extension to this finding, Atay and Kurt (2006) investigated the effectiveness of different types of post-reading activities. They compared learners performing discrete written tasks to learners doing written and interactive tasks after reading. Results showed that learners who engaged in the interactive tasks after reading performed significantly better on the Vocabulary Knowledge Scale (YKS) and CYLET tests. There has also been a comparison study of contextual learning and memory strategy. Atay and Ozbulgan (2007) compared learners in a contextual learning + memory strategy group with learners in a contextual-learningonly group. Results from a vocabulary knowledge test revealed higher gains in the contextual learning+memory strategy group.

According to the studies reviewed above, different studies have compared their intervention with other different types of instruction. However, they do have one thing in common. That is, the comparison group, whether traditional or not, and the experimental group differ in terms of an additional treatment in the experimental group. An addition of a single element makes it possible to make claims about the influence of that variable on learners' larger gain in the experimental group. Furthermore, traditional instruction is a relative term that depends on the context of the study. Therefore, our study instead used a comparison group that possessed the same elements as the experimental group but the addition of the concordancing exercises.

\subsection{Learning Principles for Vocabulary Learning}

This section reviews learning principles that are critical for vocabulary learning to occur. These principles were used as underlying principles for the creation of innovative concordancing instruction. It takes an extended period of time to learn and know words. Words must be encountered and reencountered numerous times in order to be acquired. According to Nation (1990), learners need to be exposed to a word five to sixteen or more times in order to acquire it. Rott (1999) and Ghadirian (2002) claimed that learners need twenty encounters of words before they can be acquired. The high number of exposure before vocabulary acquisition can occur makes it challenging to second language learners, particularly EFL learners. EFL learners such as Iranian learners learning English in Iran have minimal exposure to English. They study English in a formal classroom setting for only three hours a week; little English, if not none, is required outside of the classroom. In such setting, opportunities to encounter and reencounter the same words are limited, and it may take a year or several years before learners will eventually learn them (or may not acquire them at all).

Schmitt (1998) investigated how advanced L2 Japanese learners acquired different aspects of word knowledge (spelling, meaning senses, grammatical behavior, and associated words) of eleven words over a course of one academic year. He found that learning words in such context is a long and incremental process. While the knowledge of written form and grammatical knowledge improved and learners seemed to have less trouble with (due to their high language ability), other aspects of word knowledge (i.e., definitional knowledge and association knowledge) seemed to stay at the same level after one academic year, indicating that they had partial knowledge and "nowhere near full productive mastery" (p. 6).

Similarly, Bahns and Eldaw (1993) suggested that EFL learners should be taught collocation because collocation knowledge did not go hand in hand with lexical knowledge. Learners would not notice and be able to acquire word collocations and how they were used in sentences, leading to poor performance in their language production (Nesselhauf, 2004). In addition, converting receptive knowledge to productive vocabulary knowledge takes a long time (Schmitt, 2008). In an EFL setting, after years of English learning, learners may not acquire words and may not be able to convert their receptive knowledge to productive knowledge at all. Effective vocabulary instruction that can help extend learners' productive vocabulary knowledge is very much needed.

Concordancing instruction has been shown to be successful in enhancing vocabulary knowledge. Its benefits are contributed to the unique characteristics of concordance-based methods. That is, learners are exposed to rich and authentic language, and they are learning vocabulary in multiple contexts. However, based on the review of previous studies and the results of our pilot study, concordancing instruction has not yet shown to be effective. The ineffective implementation of concordance-based methods is attributable to two reasons. 
First, in terms of learning effects, all studies (except Cobb, 1999; Kaur \& Hegelheimer, 2005) found that learners improved both receptive knowledge (definitional knowledge) and productive knowledge (transfer of knowledge to new contexts). The productive knowledge claimed, however, was actually limited production or 'recall' (i.e., ability to recall meaning of the word) not 'use' (i.e., ability to use words in their own production) since the measure used in these studies was a gap-filling format. Results from such task type may not be used to make inference about learners' actual ability to use words in their production (Read, 2000). In fact, studies by Cobb (J999) and Kaur and Hegelheimer (2005) did show that learners did not improve their productive knowledge (i.e., writing ability) over time after concordancing instruction.

Second, classroom periods may not be efficiently spent on learning words. In Kaur and Hegelheimer (2005), learners learned only 30 words over a course of 12 weeks, approximately 2.5 words per week. Similarly, participants in our pilot studies were able to cope with only three to four words in one session, one and a half hours per week. The unsatisfactory results concerning learners' production and the inefficiency of class time spent on concordancing instruction may be due to the lack of the incorporation of sound principles for vocabulary learning in concordancebased methods. Learners need to be instructed under learning conditions that encourage vocabulary acquisition to occur. The following is the discussion of the principles used in the innovative concordancing instruction in the current study.

- Repeating and recycling

-Noticing

-Reflection

-Teaching different aspects of vocabulary knowledge

-Task-induced involvement

\section{Methodology}

\subsection{Research Design}

In this study, the participants were not randomly assigned but admitted to the study institution according to both their scores on the entrance exam and the major they selected, and were therefore placed in classes which, intact, were used in the study. Thus, the quantitative part of this research was quasi-experimental. As Seliger and Shohamy (1989) point out, a quasi-experimental research is less intrusive and disruptive; it avoids reorganization of classes and disturbing the ongoing program; and it is easier to obtain access to the participant populations and easier to conduct the research. It is also commonly used in educational research.

\subsection{Participants}

One of the objectives of the course was to improve the students' vocabulary knowledge based on innovative concordancing instruction (ICI) and traditional concordancing instruction. The participants were solicited directly by the researchers at the beginning of their classes. They were 90 male and female students learning English at undergraduate level at the Islamic Azad University in Iran. The students' ages ranged from 18 to 24, with the mean of 21. In addition, some students had completed 12 years of schooling and some of them had graduated from different universities in Iran at BA level and some were following their education at high school.

In determining the sample, the researchers employed three intact classes as two experimental groups including innovative concordancing instruction (ICI) group and traditional concordancing group and one control group without any kind of instruction based on concordancing while they were taught based on traditional method of vocabulary instruction. Although the participants selected for this study were studying English at the same level determined by the institute, the level of proficiency of the participants was determined by Nelson proficiency test consisting of 40 questions. Then, based on the normal probability curve, those participants who placed between one standard deviation above the mean and one standard deviation below the mean were selected as the main participants. It should be pointed out that some of the entire participants were dropped from the study due to their absence in some treatment sessions or due to incomplete data, resulting in 58 students. 


\subsection{Instruments}

The instruments used for collecting quantitative data consisted of a proficiency test, a pre-test, and a post-test. They are described in the following subsections.

\subsubsection{Proficiency Test}

A proficiency test was created to measure participants' language proficiency. This test was tested for its difficulty and discrimination indices and reliability in a pilot study. Its first version consisted of 70 items and was pilot-tested with 40 first-year university students, who were a different group from the participants in the pilot study and participants in the present study. An item analysis of the test items was conducted and only items that had a difficulty index between 0.2-0.8 and a discrimination index higher than 0.3 were selected and included in the final version. The final version of the test was comprised of 36 items and had a reliability using Cronbach's alpha of.78.

\subsubsection{Vocabulary Pre-test and Post-test}

To track learners' gain of vocabulary knowledge, an achievement test was developed and used as a pret-est and posttest, and delayed post-test. The pre-test contained 60 words selected by two EFL teachers. Forty eight words were selected from the pre-test and used in the post-test. Thirty six words were unknown words; twelve words were words that students knew their definition but not yet were able to use them in their production.

The test was comprised of two sections. The first section was similar to the test used in Horst, Cobb, and Nicolae (2005) which was adapted from Vocabulary Knowledge Scale (VKS) developed by Paribakht and Wesche (1998). This test type was used because it could assess both receptive and productive knowledge (Schmitt, 2000). The receptive knowledge was assessed by asking learners to supply translation or synonym of the word, and the productive knowledge was measured by having learners demonstrate their understanding of the meaning of a word and ability to use it in a sentence. An example of answering the test is as follows:

Instructions: What do you know about these words? Please circle 1, 2, or 3 and complete.

\section{Attach}

1. I don't know what this word means.

2. I'm not sure. I think it means. (Give the meaning in Farsi or English.)

3. I know this word. It means and I can use it in a sentence. (Write the sentence.)

In the current study, the underlying meaning of a word was the target and tested, and different meanings of words were accepted. Second, a sentence would be scored both semantically and syntactically. In regards to scoring procedures, different from VKS that gave only one score, in this study, two scores were awarded, one for reception and the other for production. A score on receptive knowledge was measured from a translation or synonym supplied by learners either in Levels 2 or 3. A score on productive knowledge was assessed from the sentence writing section in Level 3. The full score for sentence writing was 1. A score of 0.50 was given when learners gave a correct definition, and a score of 0.50 was awarded when the word was used with appropriate inflection, collocation, or linking verbs (e.g., the auxiliary verb be with a past participle in a passive voice structure).

The second section of the test also aimed at testing productive vocabulary, but at an extended writing level. In this section, learners were given a list of target words and required to use as many target words as possible to answer the prompt given (i.e., you can change one thing about Iran, what is it and why?). This prompt was chosen because it was related to the reading passages in the developed instructional materials. This test aimed to assess whether learners were able to use target words in their actual production when required to produce free writing. Every instance of the use of the target word in the participants' essays was marked for semantic appropriateness and accuracy. For semantic appropriateness, a score of 1 was awarded when words used carried appropriate meaning, and a score of 0 was given when the meaning of the word was incorrect (e.g., using acknowledge to mean knowledge). For accuracy, a score of 1 was given when the word was grammatically correct, a score of 0.5 was given when there was one mistake and the word collocation was correct, a score of 0 was given when there were more than two mistakes and the collocation was incorrect. If the meaning of the word was not correct, the accuracy was not marked. The decision to mark both semantic appropriateness and accuracy instead of the count of instances of target words used in the essay was made based upon the evidence from students' essays. It was found that some students just randomly put words in their essays with no 
real meaning. To assess the reliability of the score marking, inter-rater reliability was conducted. Thirty six essays from all groups and all three tests (three essays from each group and three from each test) were selected. The selected essays were marked by two raters. The reliability of the inter-rater reliability for semantic appropriateness was .91 and .90 for accuracy.

\subsection{Data Collection Procedure}

In order to collect the data required for the fulfillment of the objectives, a lengthy procedure was taken. At the beginning, the participating teachers were informed about the study and the types of focus on form instruction to be used in their related classes. At the very beginning of the experiment, a diagnostic test was first administered to verify whether the two groups of the participants were comparable in terms of treatment of the two respective groups or not. Finally, the results of those students placed between +1SD and -1SD were considered for data analysis. The participants then took a vocabulary pre-test in order to check the receptive and productive vocabulary knowledge based on the above-mentioned materials.

In the next procedure, the three selected groups were exposed to the treatment procedure as explained above. That is, one group was taught based on innovative concordancing instruction, another group based on traditional concordancing instruction and there was no instruction for the participants in control group. Finally, after the treatment, both groups took the post-test for checking both receptive and productive knowledge as explained in the previous sections. At the end, the results of the students' performance in pre-test and post-test were compared to answer the research questions raised.

\subsection{Data Analysis}

The collected data from the TCI, ICI, and control group on the pre-test, and post-test were compared by using gain score and ANOVAs. The results were analyzed to examine whether there were gains that were significantly different at a $<.05$ level (confidence interval 95\%) between tests within groups and between groups after eight-hour instruction for the effects of the TCI and ICI.

\section{Results}

Research question 1: Does innovative concordancing instruction result in receptive vocabulary learning when compared to traditional concordancing instruction method?

Table 1. Descriptive statistics for immediate post-test scores among ICI, TCI, and control group on receptive knowledge

\begin{tabular}{|c|c|c|c|c|c|c|c|c|}
\hline & \multirow[t]{2}{*}{$\mathrm{N}$} & \multirow[t]{2}{*}{ Mean } & \multirow[t]{2}{*}{ Std. Deviation } & \multirow[t]{2}{*}{ Std. Error } & \multicolumn{2}{|c|}{$\begin{array}{l}\text { 95\% Confidence Interval for } \\
\text { Mean }\end{array}$} & \multirow[t]{2}{*}{ Minimum } & \multirow[t]{2}{*}{ Maximum } \\
\hline & & & & & Lower Bound & Upper Bound & & \\
\hline ICI & 21 & 26.86 & 4.151 & .906 & 24.97 & 28.75 & 18 & 32 \\
\hline TCI & 20 & 17.35 & 2.059 & .460 & 16.39 & 18.31 & 14 & 21 \\
\hline Control & 18 & 9.72 & 1.227 & .289 & 9.11 & 10.33 & 8 & 12 \\
\hline Total & 59 & 18.41 & 7.577 & .987 & 16.43 & 20.38 & 8 & 32 \\
\hline
\end{tabular}

This question examined immediate instructional effects of ICI compared with TCI, and a control group on receptive knowledge. An ANOVA was conducted to compare the participants' post-test scores to examine whether they were at the same level after the instruction. As the $\mathrm{F}$ value of 178.878 was found to be significant at $0.001(\mathrm{~F}(2,56)=$ $178.878, \mathrm{P}<.05)$, the results showed a significant difference among the effect of concordancing instruction on three groups (Table 2). Further, the mean scores of the samples in ICI, TCI, and control group were found to be 26.86 , 17.35 , and 9.72 respectively, which are statistically different. 
Table 2. Results of ANOVA for the effect of ICI, TCI, and control group on receptive knowledge

\begin{tabular}{llllll}
\hline & Sum of Squares & Df & Mean Square & F & Sig. \\
\hline Between Groups & 2879.505 & 2 & 1439.752 & 178.878 & .000 \\
Within Groups & 450.733 & 56 & 8.049 & & \\
Total & 3330.237 & 58 & & & \\
\hline
\end{tabular}

Now, in order to see where the difference stands, the post hoc Scheffe test (Table 3) showed that the ICI group performed significantly better than TCI group (26.86 vs. 17.35). In other words, teaching vocabulary based on ICI was recognized to be more effective method than TCI.

Table 3. Post hoc Scheffe test

\begin{tabular}{|c|c|c|c|c|c|}
\hline & Group & $\mathrm{N}$ & Subs & pha $=$. & \\
\hline & & & 1 & 2 & 3 \\
\hline \multirow[t]{4}{*}{ Scheffe $(a, b)$} & Control & 18 & 9.72 & & \\
\hline & TCI & 20 & & 17.35 & \\
\hline & ICI & 21 & & & 26.86 \\
\hline & Sig. & & .001 & .001 & .001 \\
\hline
\end{tabular}

Research question 2: Does innovative concordancing instruction result in productive vocabulary learning when compared to traditional concordancing instruction method?

Table 4. Descriptive statistics for immediate post-test scores among ICI, TCI, and control group on productive knowledge

\begin{tabular}{|c|c|c|c|c|c|c|c|c|}
\hline & \multirow[t]{2}{*}{$\mathrm{N}$} & \multirow[t]{2}{*}{ Mean } & \multirow[t]{2}{*}{ Std. Deviation } & \multirow[t]{2}{*}{ Std. Error } & \multicolumn{2}{|c|}{$\begin{array}{c}\text { 95\% Confidence Interval } \\
\text { for Mean }\end{array}$} & \multirow[t]{2}{*}{ Minimum } & \multirow[t]{2}{*}{ Maximum } \\
\hline & & & & & Lower Bound & Upper Bound & & \\
\hline ICI & 21 & 19.05 & 3.041 & .664 & 17.66 & 20.43 & 15 & 27 \\
\hline TCI & 20 & 13.85 & 2.277 & .509 & 12.78 & 14.92 & 9 & 18 \\
\hline Control & 18 & 10.06 & 1.162 & .274 & 9.48 & 10.63 & 8 & 12 \\
\hline Total & 59 & 14.54 & 4.364 & .568 & 13.41 & 15.68 & 8 & 27 \\
\hline
\end{tabular}

As it is clear from Table 5, ANOVA revealed a significant difference between the ICI, TCI, and control group with regard to the effect of teaching based on concordancing instruction on vocabulary retention, where the obtained $\mathrm{F}$ value was 72.931 and P value was .000. Further, mean scores of the samples in ICI, TCI, and control group were found to be $19.05,13.85,10.06$, respectively, which are statistically different. 
Table 5. Results of ANOVA for instructional effects on productive vocabulary

\begin{tabular}{lccccc}
\hline & Sum of Squares & Df & Mean Square & F & Sig. \\
\hline Between Groups & 798.197 & 2 & 399.099 & 72.931 & .000 \\
Within Groups & 306.447 & 56 & 5.472 & & \\
Total & 1104.644 & 58 & & & \\
\hline
\end{tabular}

Now, in order to see where the difference stands, the post hoc Scheffe test (Table 4) showed that the ICI group performed significantly better than TCI group (29.05 vs. 13.85). In other words, teaching vocabulary based on ICI was recognized to be more effective method than TCI.

Table 6. Post hoc Scheffe test

\begin{tabular}{cccccc}
\hline & Group & N & \multicolumn{3}{c}{ Subset for alpha $=.05$} \\
\hline \multirow{3}{*}{ Scheffe(a,b) } & & 1 & 2 & 3 \\
& Control & 18 & 10.06 & & \\
& TCI & 20 & & 13.85 & 19.05 \\
& ICI & 21 & .001 & .001 & .001 \\
& Sig. & & & & \\
\hline
\end{tabular}

Research question 3: Does innovative concordancing instruction result in learners' retention of receptive vocabulary knowledge when compared to traditional concordancing instruction method?

Table 7. Descriptive statistics for delayed post-test gain scores among ICI, TCI, and control group on receptive knowledge

\begin{tabular}{|c|c|c|c|c|c|c|c|c|}
\hline & \multirow[t]{2}{*}{$\mathrm{N}$} & \multirow[t]{2}{*}{ Mean } & \multirow[t]{2}{*}{ Std. Deviation } & \multirow[t]{2}{*}{ Std. Error } & \multicolumn{2}{|c|}{$\begin{array}{l}\text { 95\% Confidence Interval for } \\
\text { Mean }\end{array}$} & \multirow[t]{2}{*}{ Minimum } & \multirow[t]{2}{*}{ Maximum } \\
\hline & & & & & Lower Bound & Upper Bound & & \\
\hline$\overline{\mathrm{ICI}}$ & 21 & .38 & 1.244 & .271 & -.19 & .95 & -1 & 2 \\
\hline TCI & 20 & -1.40 & 2.162 & .483 & -2.41 & -.39 & -5 & 5 \\
\hline Control & 18 & -.22 & .943 & .222 & -.69 & .25 & -2 & 1 \\
\hline Total & 59 & -.41 & 1.703 & .222 & -.85 & .04 & -5 & 5 \\
\hline
\end{tabular}

This question examined delayed instructional effects of ICI compared with TCI, and a control group on receptive knowledge. An ANOVA was conducted to compare the participants' delayed post-test scores to examine whether they were at the same level after the instruction or not. As the $F$ value of 6.929 was found to be significant at 0.001 ( $F(2$, $56)=6.929, \mathrm{P}<.05)$, the results showed a significant difference among the effect of concordancing instruction among the three groups (Table 8). 
Table 8. Results of ANOVA for the delayed effect of ICI, TCI, and control group on receptive knowledge

\begin{tabular}{lccccc}
\hline & Sum of Squares & Df & Mean Square & F & Sig. \\
\hline Between Groups & 33.374 & 2 & 16.687 & 6.929 & .002 \\
Within Groups & 134.863 & 56 & 2.408 & & \\
Total & 168.237 & 58 & & & \\
\hline
\end{tabular}

Now, in order to see where the difference stands, the post hoc Scheffe test (Table 9) showed that the ICI group performed significantly better than TCI group (.38 vs. -1.40). As a result, teaching vocabulary based on ICI was recognized to be more effective method than TCI as far as the retention of concordancing instruction is concerned. By looking at mean table, we can see that the mean delayed gain score of TCI and control is negative which means that the students' performance during the delayed post-test stage has decreased while this amount is positive for the students' performance in ICI group.

Table 9. Post hoc

\begin{tabular}{llll}
\hline Group & $\mathrm{N}$ & Subset for alpha $=.05$ & \\
\hline & & 1 & 2 \\
TCI & 20 & -1.40 & \\
Control & 18 & -.22 & -.22 \\
ICI & 21 & & .38 \\
Sig. & & .068 & .482 \\
\hline
\end{tabular}

Research question 4: Does innovative concordancing instruction help learners retain their productive vocabulary when compared to traditional concordancing instruction method?

Table 10. Descriptive statistics for delayed posttest scores among ICI, TCI, and control group on productive knowledge

\begin{tabular}{|c|c|c|c|c|c|c|c|c|}
\hline & $\mathrm{N}$ & Mean & Std. Deviation & Std. Error & $\begin{array}{l}\text { 95\% Confide } \\
\text { Mean }\end{array}$ & ice Interval & forM & Maximum \\
\hline & & & & & Lower Bound & Upper Bound & & \\
\hline ICI & 21 & .43 & 1.630 & .356 & -.31 & 1.17 & -3 & 2 \\
\hline TCI & 20 & -1.35 & 2.412 & .539 & -2.48 & -.22 & -6 & 5 \\
\hline Control & 18 & -.22 & 1.396 & .329 & -.92 & .47 & -2 & 2 \\
\hline Total & 59 & -.37 & 1.990 & .259 & -.89 & .15 & -6 & 5 \\
\hline
\end{tabular}

As it is clear from Table 11, ANOVA revealed a significant difference between the ICI, TCI, and control group with regard to the effect of teaching based on concordancing instruction on vocabulary retention, where the obtained $\mathrm{F}$ value was 5.216 and P value was .008. Further, the mean scores of the samples in ICI, TCI, and control group were found to be $.43,-1.35$, and -.22 , respectively, which are statistically different. 
Table 11. Results of ANOVA for delayed instructional effects on productive vocabulary

\begin{tabular}{lccccc}
\hline & Sum of Squares & Df & Mean Square & F & Sig. \\
\hline Between Groups & 33.043 & 2 & 16.522 & 5.216 & .008 \\
Within Groups & 177.363 & 56 & 3.167 & & \\
Total & 210.407 & 58 & & & \\
\hline
\end{tabular}

Now, in order to see where the difference stands, the post hoc Scheffe test (Table 12) showed that the ICI group performed significantly better than TCI group (.43 vs. -1.35$)$. In other words, teaching vocabulary based on ICI was recognized to be more effective method for the retention of new words than TCI. In other words, by looking at mean table, we can see that the mean delayed gain score of TCI and control is negative which means that the students' performance during the delayed post-test stage has decreased while this amount is positive for the students' performance in ICI group.

Table 12. Post hoc Scheffe test

\begin{tabular}{lcccc}
\hline & Group & $\mathrm{N}$ & \multicolumn{2}{c}{ Subset for alpha $=.05$} \\
\cline { 4 - 5 } & & & 1 & 2 \\
\hline Tukey B(a,b) & TCI & 20 & -1.40 & \\
& Control & 18 & -.28 & -.28 \\
& ICI & 21 & & .38 \\
\hline Scheffe(a,b) & TCI & 20 & -1.40 & \\
& Control & 18 & -.28 & -.28 \\
& ICI & 21 & & .38 \\
& Sig. & & .152 & .515 \\
\hline
\end{tabular}

\section{Discussion}

The main objective of this study was to examine the effectiveness of innovative concordancing instruction (ICI) on receptive and productive vocabulary knowledge compared with traditional concordancing instruction (TCI), and a control group. The results from the immediate post-test revealed that two experimental groups outperformed the control group. ICI learners, however, did not perform statistically significantly better than learners in TCI in both receptive and productive knowledge.

The significant differences between the experimental groups and the control group demonstrated that the two instructional methods were effective in enhancing learners' vocabulary receptive and productive knowledge. Further, the significant differences among the two instructional methods revealed that IC yielded similar instructional effects on the enhancement of learners' receptive and productive knowledge. The results of the study were useful. More importantly, the results of the study emphasize a critical role of teaching different facets of vocabulary knowledge. Previous literature on vocabulary instruction has emphasized the importance of learners possessing different aspects of vocabulary knowledge if they want to be able to use words in production (Nation, 2008; Schmitt, 2008). This present study provided empirical evidence to this element of vocabulary instruction.

Previous vocabulary studies largely focused on the improvement of receptive knowledge (i.e., word meaning). Even though this seems to be useful to learners because learners need a substantial amount of receptive knowledge to be able to comprehend a text, having only definitional knowledge has limited impact on textual comprehension and 
production (Koda, 2005). Furthermore, even though learners need receptive knowledge at an early stage of vocabulary learning, it takes a great amount of time and multiple exposures to words in order for learners to convert their receptive knowledge of the words to productive knowledge (Coxhead \& Byrd, 2007). Nation (1990) mentioned that learners need to be exposed to a word five to sixteen or more times in order to acquire it.

Rott (1999) and Ghadirian (2002) raised the number of word encounters to twenty. Laufer (2003) further asserts that to have at least 10 exposures to a word, learners need to read 1-2 graded readers per week, and typical learners do not have that much reading to support vocabulary learning. What Laufer implies is that it is very challenging for learners to acquire different aspects of a word because learners do not have sufficient exposure to it. The high number of exposure before vocabulary acquisition can occur is even more challenging to EFL learners because this group of learners such as Iranian EFL learners learning English in Iran has minimal exposure to English. They study English in a formal classroom setting for only three hours a week; little English, if not none, is required outside of the classroom. In such setting, opportunities to encounter and reencounter the same words are limited, and it may take a year, or several years, before learners will eventually learn them (or maybe not at all). The results of the study showing that teaching different aspects of vocabulary knowledge greatly helped enhance learners' both receptive and productive knowledge in one semester are tremendously beneficial to vocabulary instruction in such context.

The instructional approaches used in this study were also supported by Schmitt (2008). Schmitt reviewed previous articles on instructed second language vocabulary learning and concluded that four factors facilitating vocabulary learning are exposure, attention, manipulation, and time spent on lexical items. These four factors together are called engagement. Schmitt stated that the higher and the better the engagement, the more vocabulary learning will improve. Also, these four elements of engagement proposed by Schmitt were four main elements of the 17 implications for effective vocabulary learning and teaching suggested by Grabe (2009). According to Grabe, these features should be the main parts of the development of vocabulary instruction and a vocabulary-learning curriculum. Hence, vocabulary instruction should take into consideration the integration of concordancing instruction with these instructional approaches when designing vocabulary curricular and/or planning lessons.

Further, the comparisons of the immediate post-test and delayed post-test on receptive knowledge revealed that in ICI experimental groups, the impact of instruction remained persistent in the delayed post-test two weeks after the instruction. However, these results were not confirmed for the effect of TCI method of instruction. When retention was compared, all groups were significantly different. As such, it can be concluded that ICI yielded better instructional effects on receptive and productive knowledge when compared to TCI and control group. In fact, among the two methods, IC was more effective in helping learners retain definitional knowledge. This result was interesting because ICI learners performed very well on the measures of definitional knowledge in the immediate post-test as well as better in the delayed post-test. However, as far as the reduction of the efficiency of student's performance in TCI instruction may show some sign of a U-Shape phenomenon (Gass \& Selinker, 2001). When learning a language, learners seem to be able to perform well after the instruction. Later, it seems they forget about it, and then they seem to get things right again. According to Sjoholm (1989, as cited in Gass \& Selinker, 2001), the U-shape phenomenon often occurs with the learning of lexical items when the conveying of semantic relations was required. Also, they were required to write an essay using the target words. This type of test may lead to test exhaustion, particularly at the end of the semester when most class projects were due and the final exams were approaching. When learners are uninterested and do not try hard enough in taking the test, scores may not correctly reveal learners' actual vocabulary knowledge (Nation, 2008).

It is not a surprise that ICI was a more effective method in enhancing learners' use of words in new sentences. This result is due to the fact that sentence writing was the main practice in ICI. As such, if the main purpose of the course is to develop learners' writing at a sentence level, this teaching type should be adopted. The strongest effect size of ICI and the significant differences found between ICI and TCI in the two measures of extended writing (Productive knowledge) may be due to the higher level of engagement in ICI than in TCI (Schmitt, 2008). With ICI instruction, learners repeatedly encountered the target words. Also, they were required to use them in different meaning-focused and word-focused activities: reading, answering comprehension questions, searching for word families, collocations, and grammatical patterns from a concordancer, and writing an essay, compared with searching for word families, collocations, and grammatical patterns, and writing a sentence in TCI. As mentioned, curriculum designers and lesson planners should consider adopting engagement and concordancing instruction to enhance deeper levels of vocabulary learning. 


\section{Conclusion}

In the light of the results of the study, the following conclusions can be made. First, the most important finding of this study is that ICI was beneficial to help learners enhance and retain their use of the target words in extended writing, and it was as effective as other methods in helping learners develop and retain their definitional knowledge. This may be explained in terms of the combination effects of concordancing instruction and critical principled instructional approaches. These two factors together increased the level of learners' engagement in learning vocabulary. However, it should be noted that the results may be questionable due to the fact that the target words consisted of two groups: unknown words and words that learners knew their definitions but they were not yet able to use the words in their production. Since it was not the plan of the present study to track learners' improvement of each word, it was not certain if the words used in the extended writing were actually the unknown words or the words that their definitions were known. Future studies should either use only unknown words as target words or keep track of each word if partially learned words are included.

Second, it is important to note that teaching different aspects of vocabulary knowledge should be one part of vocabulary curriculum if a higher level of vocabulary knowledge beyond definitional knowledge is expected. Third, the results of this study add another jigsaw puzzle piece to concordancing literature concerning the use of concordancebased methods with learners at undergraduate level. These results, however, need to be taken with some caution due to a small sample size in this group. Future studies with a greater sample size in both groups will lead to a better understanding of the effects of concordancing instruction on learners with different language abilities. Finally, innovative concordancing instruction was found to be the most effective method in enhancing learners' ability to use the target words in sentences. This technique should be used if the main purpose of the lesson is to improve learners' vocabulary use at a sentence level.

\section{Pedagogical Implications}

The current study provides several implications for vocabulary language instruction. When designing vocabulary curricula and developing materials for EFL learners, teachers should consider the following:

First, the integration of concordancing instruction and different instructional principles critical for vocabulary learning (e.g., repeating and recycling, noticing, reflecting, etc.) should be one of the major features in vocabulary lessons and as one of the curricula goals. As mentioned, learners need a great number of exposures to a word before they can acquire it. Learners do not learn words from meeting them once. As such, vocabulary items should be introduced and reintroduced to learners in different activities throughout course. These principles when combined with the use of concordancing instruction, known as innovative concordancing instruction created in this study, could provide learners with greater opportunities for engagement and higher achievement in language production.

Second, teaching different aspects of vocabulary knowledge should be included if the main purpose of the class is to enhance both receptive and productive vocabulary knowledge. Even though definitional knowledge is crucial for textual comprehension and the development of productive knowledge, it takes a great amount of time for learners to encounter different aspects of vocabulary knowledge and to convert their definitional knowledge to the productive one. Most EFL learners do not have sufficient exposure in order to encounter and reencounter the words. As a result, most words are forgotten and unlearned, resulting in poor language comprehension and performance. Teaching multiple facets of word knowledge through innovative concordancing instruction may help shorten this process.

Third, when the main purpose is to improve learners' writing at a sentence level, it may be more appropriate to adopt Innovative concordancing instruction. As the results of the study suggested, innovative concordancing instruction was the most effective method in enhancing writing at a sentence level. This is due to the fact that learning through concordancing instruction, learners are exposed to multiple sample sentences and are given opportunities to practice writing sentences in class.

\section{References}

Atay, D., \& Kurt, G. (2006). Elementary school EFL learners' vocabulary learning: The effects of post-reading activities. The Canadian Modern Language Review, 63(2), 255-273. doi.org/10.3138/cmlr.63.2.255.

Atay, D., \& Ozbulgan, C. (2007). Memory strategy instruction, contextual learning and ESP vocabulary recall. English for Specific Purposes, 26(1), 39-51. https://doi.org/10.1016/j.esp.2006.01.002 
Bahns, J., \& Eldaw, M. (1993). Should we teach EFL students collocations? System, 21(1), 101-114. https://doi.org/10.1016/0346-251X(93)90010-E

Cobb, T. (1999). Breadth and depth of lexical acquisition with hands-on concrodancing. Computer Assisted Language Learning, 12(4), 345-360. doi: 10.1076/call.12.4.345.5699

Coxhead, A., \& Byrd, P. (2007). Preparing writing teachers to teach the vocabulary and grammar of academic prose. Journal of Second Language Writing, 16(3), 129-147. http://dx.doi.org/10.1016/j.jslw.2007.07.002

de la Fuente, M. J. (2006). Classroom L2 vocabulary acquisition: investigating the role of pedagogical tasks and formfocused instruction. Language Testing Research, 10(3), 263-295. doi.org/10.1191/13621688061r1960a

Gan, S. L., Low, F., \& Yaakub, N. (1996). Modeling teaching with a computer-based concordancer in a TESL preservice teacher education program. Journal of Computing in Teacher Education, 12(4), 28-32. doi: $\underline{10.1080 / 10402454.1996 .10784301}$

Gass, S. M., \& Selinker, L. (2001). Second language acquisition: An introductory course (2nd edition). Mahwah, NJ: Lawrence Erlbaum Associates.

Ghadirian, S. (2002). Providing controlled exposure to target vocabulary through the screening and arranging of texts. Language Learning \& Technology, 6(1), 147-164. Retrieved April, 2018 from https://www.lltjournal.org/item/2377

Grabe, W. (2009). Reading in a second language: Moving/rom theory to practice. Cambridge: Cambridge University Press.

Horst, M., Cobb, T., \& Nicolae, I. (2005). Expanding academic vocabulary with an interactive on-line database. Language Learning, \& Technology, 9(2), 90-110 Retrieved March, 2018 from https://www.lltjournal.org/item/2508

Hunston, S. (2002). Corpora in applied linguistics. Cambridge: Cambridge University Press.

Kaur, J., \& Hegelheimer, V. (2005). ESL students' use of concordance in the transfer of academic word knowledge: An exploratory study. Computer Assisted Language Learning, 18(4), 287-310. https://doi.org/10.1080/09588220500280412

Koda, K. (2005). Insights into second language reading. NY: Cambridge University Press.

Laufer, B. (2003). Vocabulary acquisition in a second language: Do learners really acquire most vocabulary by reading? Some empirical evidence. The Canadian Modern Language Review, 59(4), 567-587. https://doi.org/10.3138/cmlr.59.4.567.

Laufer, B., \& Hulsjin, L. (2001). Incidental vocabulary acquisition in a second language: The construct of taskinduced involvement. Applied Linguistics, 2(1), 1-26. https://doi.org/10.1093/applin/22.1.1.

Meara, P., \& Fitzpatrick, T. (2000). Lex30: An improved method of assessing productive vocabulary in an L2. System, 28(1), 19-30. http://dx.doi.org/10.1016/S0346-251X(99)00058-5.

Nation, I. S. P. (1990). Teaching and learning vocabulary. Boston: Heinle \& Heinle Publishers.

Nation, I. S. P. (2008). Teaching vocabulary: Strategies and techniques. MA: Heinle.

Nesselhauf, N. (2004). Collocations in a learner corpus. Philadelphia: John Benjamins.

Newton, J. (1995). Task-based interaction and incidental vocabulary learning: A case study. Second Language Research, 11(2), 159-177. https://doi.org/10.1177/026765839501100207

Paribakht, T. S., \& Wesche, (1998). The relationship between passive and active vocabularies: Effects of language learning context. Language Learning, 48(4), 365391.

Read, J. (2000). Assessing vocabulary. Cambridge: Cambridge University Press. 
Rott, S. (1999). The effect of exposure frequency on intermediate language learners' incidental vocabulary acquisition and retention through reading. Studies in Second Language Acquisition, 21(4), 589-620. https://doi.org/10.1017/S0272263199004039.

Schmitt, N. (1998). Tracking the incremental acquisition of second language vocabulary: A longitudinal study. Language Learning, 48(2), 281-317. https://doi.org/10.1111/1467-9922.00042

Schmitt, N. (2000). Vocabulary in language teaching. Cambridge: Cambridge University Press.

Schmitt, N. (2008). Instructed second language vocabulary learning. Language Teaching Research, 12, 329-363. https://doi.org/10.1177/1362168808089921.

Seliger, H. W., \& Shohamy, E. (1989). Second language research methods. Oxford: Oxford University Press.

Supathanon, P. (2005). A comparison of the effects of the concordance-based and the conventional teaching methods on engineering students' English vocabulary learning. Unpublished doctoral dissertation, Chulalongkorn University, Thailand. 